\title{
O direito à convivência familiar de crianças e adolescentes: uma análise da responsabilidade civil por desistência de adoção
}

\author{
The right to family life for children and adolescents: \\ an analysis of civil liability for giving up adoption
}

\author{
André Viana CustóDio \\ Universidade de Santa Cruz do Sul - UNISC \\ MaUrício NADER GriguC \\ Universidade de Santa Cruz do Sul - UNISC
}

RESUMo O tema do artigo é adoção, mais especificamente a desistência da adoção e a possibilidade de responsabilização civil por danos morais sofridos pelos adotados. O objetivo é estudar a responsabilidade civil por desistência de adoção como dimensão de garantia do direito à convivência familiar de crianças e adolescentes. O problema questiona quais são as limitações para que se garanta o direito à responsabilização civil decorrente de danos morais suportados por crianças e adolescentes vítimas de adoções frustradas. A hipótese considera que a proteção legal relativa às desistências de adoções na legislação Brasileira não é precisa, deixando subentendido que o dano moral nesses casos se alicerça no Código Civil, o que pode gerar, em muitas situações, a inobservância do direito. O método de abordagem foi dedutivo e o método de procedimento monográfico com técnicas de pesquisa bibliográfica e documental. Conclui-se que a indenização por danos morais às crianças e adolescentes vítimas de desistência de adoção é cabível em qualquer momento, inclusive nas desistências ocorridas durante o estágio de convivência, desde que comprovado que se constituiu vínculo de intensidade tão forte, capaz de desencadear prejuízos emocionais e morais ao adotado.

Palavras-chave: Adoção; Desistência; Responsabilidade civil; Dano moral; Poder FAMILIAR.

ABSTRACT The theme of the article is adoption, more specifically the withdrawal of adoption and the possibility of civil liability for moral damages suffered by the adoptees. The objective is to study civil liability for abandonment of adoption as a guarantee dimension of the right to family life for children and adolescents. The problem asks what are the limitations to guarantee the right to civil liability resulting from moral damages borne by children and adolescents who are victims of frustrated adoptions? The hypothesis considers that the legal protection re- 
garding the withdrawal of adoptions in Brazilian legislation is not accurate, implying that the moral damage in these cases is based on the Civil Code, which can lead, in many situations, to non-compliance with the law. The approach method was deductive and the method of monographic procedure with bibliographic and documentary research techniques. It is concluded that compensation for moral damages to children and adolescents victims of adoption withdrawal is applicable at any time, including withdrawals that occur during the coexistence stage, provided that it is proven that a bond of such strong intensity, capable of triggering damages, was established. emotional and moral to the adoptee.

Keywords: Adoption; Withdrawal; Civil liability; Moral Damage; Family Power.

\section{INTRODUÇÃo}

O ordenamento jurídico brasileiro, seja a partir da Constituição Federal ou das legislações infraconstitucionais, conferiu amplitude à proteção de crianças, adolescentes e jovens no país. Posteriormente, o Estatuto da Criança e do Adolescente, principal fonte de proteção jurídica dos infantes no Brasil, cuidou de especificar a prioridade absoluta decorrente da condição peculiar da pessoa em desenvolvimento.

A precária realidade econômica brasileira faz emergir seus reflexos nas famílias, consideradas base da sociedade civil como preceitua a constituição federal no artigo 226: "A família, base da sociedade, tem especial proteção do Estado" (BRASIL, 1988). Preponderantemente, por esse motivo, a adoção é instituto recorrente no cotidiano jurídico do país. A própria carta magna cuidou de estabelecer a natureza jurídica da adoção no seu texto mais tarde complementado com a promulgação do Estatuto da Criança e do Adolescente, figurando a adoção como uma das modalidades de colocação em família substituta. Também, aliando-se ao caráter humanitário do qual nasceu a lei maior, o $6^{\circ}$ do artigo 227 cuidou de proibir quaisquer discriminações, inclusive no âmbito do direito sucessório, relativas à filiação, ou seja, assegurou aos adotados, posição jurídica idêntica a dos filhos biológicos: "Os filhos, havidos ou não da relação do casamento, ou por adoção, terão os mesmos direitos e qualificações, proibidas quaisquer designações discriminatórias relativas à filiação" (BRASIL, 1988).

Mas muitos dos processos de adoção no país mostraram que do ato de afeto que é a adoção poderia, em um curto período, mostrar outras faces por parte dos adotantes que, momentaneamente tomados pelo desejo da paternidade, deixam de observar características inerentes às crianças que sofreram com a perda do vínculo com a família biológica ou nem mesmo a conheceram, surgindo o desejo e o ato de desistir da adoção, momento em que o adotado retorna ao acolhimento institucional. Evidentemente, esse segundo abandono é seguido por consideráveis abalos emocionais e morais, caracterizando, talvez, o direito de reparação civil por danos morais.

O problema de pesquisa pretende responder quais são as limitações para que se garanta o direito à responsabilização civil decorrente de danos morais suportados por crianças e adolescentes vítimas de adoções frustradas.

O método de abordagem é dedutivo, com técnica de pesquisa a partir do embasamento da investigação em bases teóricas sustentadas em livros e artigos científicos, assim como 
pesquisa documental para a análise de decisões judiciais.

O presente artigo avalia se existem ou não limitações no ordenamento jurídico brasileiro para a garantia de reparação civil pelos danos morais decorrentes da desistência da adoção, observando as legislações atuais como a Constituição Federal, o Código Civil e o Estatuto da Criança e do Adolescente, bem como buscando embasamento no instituo da responsabilidade civil.

\section{A adoção no contexto do direito à convivência familiar}

No Brasil, toda criança ou adolescente possui o direito à convivência com a entidade familiar natural, mas quando essa família não assume seus deveres parentais ou, por outras, provoque a violação de direitos, o Estado intervirá e, em última hipótese, destituirá o poder familiar, encaminhando a criança ou o adolescente para os serviços de acolhimento para uma futura adoção. O objetivo maior da adoção é esse, oferecer um ambiente adequado ao desenvolvimento de uma criança que por algum motivo precisou ser retirada do convívio com a família biológica. (RIEDE; SARTORI, 2013, p. 3).

A extinção é a interrupção definitiva da autoridade parental: "por sua gravidade, a perda da autoridade parental somente deve ser decidida quando o fato que a ensejar for de tal magnitude que ponha em perigo permanente a segurança e a dignidade do filho" (LÔBO, 2018, p. 198). Preceitua o art. 1635, V, do Código Civil vigente que ocorrerá a destituição do poder familiar por decisão judicial na forma do art. 1638. O art. 1638, por sua vez, estatui as hipóteses dessa destituição, todas elas, condutas gravosas. De todo modo, a manutenção da criança ou do adolescente na família natural ou extensa não pode ser tratada como norma absoluta, devendo sempre se observar o melhor interesse do adotado na forma do $\S 3^{\circ}$ do art. 39 , regra que decorre da doutrina da proteção integral e do melhor interesse.

\section{Os conceitos de adoção e poder familiar}

A adoção é o ato jurídico pelo qual se reconhece, de forma definitiva, a filiação de pessoa com a qual não existe vínculo consanguíneo. É prevista no artigo 28 do Estatuto da Criança e do Adolescente, sendo uma das três modalidades de inserção em uma família substituta, e busca o reestabelecimento do direito à convivência familiar para crianças e adolescentes anteriormente destituídos desse mesmo poder: "A colocação em família substituta far-se-á mediante guarda, tutela ou adoção, independentemente da situação jurídica da criança ou adolescente, nos termos desta Lei” (BRASIL, 1990).

Diniz (2020, pág. 595-597) conceitua adoção como "um ato judicial pelo qual, observados os requisitos legais, se estabelece, independentemente de qualquer relação de parentesco consanguíneo ou afim, um vínculo fictício de filiação, trazendo para uma família, na condição de filho, pessoa que, geralmente, lhe é estranha.".

Desde o advento da Constituição Federal de 1988, a adoção passou por diversas alterações. Nas últimas décadas, o ordenamento jurídico brasileiro passou a conferir cada vez mais valor jurídico à dignidade da pessoa humana e a afetividade no âmbito do direito de família, princípios que refletem de forma direta no instituto da adoção. 
Além da atenta observação que fez a Carta Magna de 1988, cuidando de excluir, expressamente, quaisquer formas de discriminação relativas ao filho adotado, o mesmo foi feito, mais tarde, pelo Código Civil na redação do artigo 1596: “Os filhos, havidos ou não da relação de casamento, ou por adoção, terão os mesmos direitos e qualificações, proibidas quaisquer designações discriminatórias relativas à filiação” (BRASIL, 2002).

Após a Constituição de 1988, não há mais filho adotivo, mas adoção, entendida como meio para filiação, que é única. A partir do momento em que a adoção se conclui, com a sentença judicial e o registro de nascimento, o adotado se converte integralmente em filho. (LÔBO, 2018, p. 198).

Concretizando o ideal de dignidade da pessoa humana sob o qual emergiu a Constituição Federal de 1988, o direito de família contemporâneo é orientado pelo princípio da afetividade que também reflete diretamente na adoção.

Por certo, a adoção se apresenta como muito mais do que, simplesmente, suprir uma lacuna deixada pela Biologia. É a materialização de uma relação filiatória estabelecida pela convivência, pelo carinho, pelos conselhos, pela presença afetiva, pelos ensinamentos, enfim, pelo amor. (FARIAS; ROSENVALD, 2017, p. 966).

Não apenas os princípios basilares da Constituição Federal ou do Direito de família repercutiram no instituto da adoção, mas, principalmente, o princípio básico do Direito da Criança e do Adolescente, o qual regula a adoção no Brasil, o melhor interesse da criança. Embora sem previsão expressa, o princípio do melhor interesse da criança "decorre da interpretação harmônica de todo o sistema jurídico referente aos direitos de crianças e adolescentes". (ZAPATER, 2019, p. 74).

O princípio da proteção integral está diretamente ligado ao chamado princípio do melhor interesse da criança e do adolescente, estampado no art. 100, parágrafo único, II do Estatuto da Criança e do Adolescente, que específica que as políticas públicas devem ser voltadas ao que melhor atende às questões pertinentes aos interesses do sujeito em desenvolvimento, buscando-se, assim, uma maior efetividade de seus direitos fundamentais (MOREIRA; MARINHO, 2019, p. 5).

O zelo com a dignidade da pessoa em desenvolvimento em que se alicerça o Direito da Criança e do Adolescente, também foi determinante para a evolução dos significados da adoção, seja para os adotantes ou para o adotado. A legislação atual evidencia que, antes de qualquer realização pessoal dos adotantes, o objetivo maior da adoção é proporcionar, em todos os aspectos, o bem-estar do adotado.

Os filhos adotivos já representaram uma forma de realização dos desejos para pessoas, matrimônios ou uniões estáveis sem descendência; com o advento da doutrina dos melhores interesses das crianças e dos adolescentes, também no instituto da adoção a prioridade deixou de ser a realização pessoal dos adotan- 
tes e passou a prestigiar os interesses superiores da criança e do adolescente, substancialmente integrando uma célula familiar, capaz de proporcionar efetiva felicidade ao adotado. (MADALENO, 2019, p. 648).

Contemporaneamente, a adoção visa assegurar plenas condições de desenvolvimento de crianças e adolescentes com base nos fundamentos inscritos na teoria da proteção integral que constitui o Direito da Criança e do Adolescente no Brasil.

\section{O processo de adoção no Brasil}

O processo de adoção no Brasil possui seis etapas principais: petição inicial de habilitação; participação em curso de preparação psicossocial e jurídica; deferimento da habilitação com a inscrição no Cadastro Nacional de Adoção; pedido de adoção; estágio de convivência; e sentença. (PEDROZA, 2017, p. 16).

O Estatuto da Criança e do Adolescente estabeleceu os procedimentos básicos para o processo de adoção entre os artigos 39 e 59-D quando trata da adoção, dos artigos 165 a 170 ao regular a colocação em família substituta e a habilitação nos artigos 197-A e 197-E. (DIAS, 2017, p. 129).

Sua burocratização e seu longo período de espera ainda dividem opiniões, entre os que sustentam que o tempo de espera gera um amadurecimento por parte dos adotantes e os que observam surgir o desestímulo dos adotantes em razão da demora no processo. Para Rezende (2014, p. 81) "o ato se reveste de inúmeras formalidades que objetivam, em última instância, avaliar a aptidão do postulante, e, sobretudo provocar nele uma reflexão acerca da seriedade do ato". Já Dias, descreve o processo de habilitação como moroso, desgastante e desestimulante, e comenta, ainda, sobre os que desejam adotar pela segunda vez, os quais devem passar por todo o trâmite novamente e "a demora do procedimento e a necessidade de aguardar por anos, desestimula o projeto de aumento da família". (DIAS, 2017, p. 123).

Inicialmente, os adotantes deverão apresentar a petição inicial acompanhada de todos os documentos exigidos pelo art. 197-A do Estatuto da Criança e do Adolescente, entre os quais estão comprovantes de renda e domicílio, atestados de sanidade física e mental e certidão de antecedentes criminais. São dois objetivos dessas condições: o primeiro é verificar a vida pregressa dos requerentes à adoção. O segundo motivo é aferir-se se haverá real vantagem ao adotante (ROSSATO; LÉPORE, 2009, p. 87). Após o envio dos autos ao Ministério Público, conforme o art. 197-B do ECA, os candidatos devem, obrigatoriamente, frequentar o curso de preparação psicossocial e jurídica, determinação do art. 50 do ECA, mas oferecido por poucas comarcas, sendo, geralmente, substituído por uma declaração de que assistiram um vídeo, o que substitui a frequência no curso. (DIAS, 2017, p. 123).

Posteriormente a etapa do curso de preparação exigida pelo $\S 3^{\circ}$ do art. 50 do Estatuto da Criança e do Adolescente, os candidatos passam pelo estudo psicossocial realizado pela equipe técnica do Juizado da Infância e Juventude, conforme estabelece o art. 197-C do Estatuto da Criança e do Adolescente, seguido de entrevistas e visitas domiciliares, momento em que os pretendentes indicarão o perfil que desejam do adotado. Em seguida, após ser preenchido o perfil adotivo, o Estado localizará uma criança ou adolescente que se assemelhe ao perfil almejado pelos pretendentes à adoção e fará a aproximação gradativa 
deles. Esse processo de aproximação das duas partes começa com encontros na instituição, passeios, até chegar a um momento em que o juiz, verificando o interesse de ambas as partes, dará início ao estágio de convivência. (PEDROZA, 2017, p. 18).

O estágio de convivência é um período de adaptações, em que adotantes e adotando terão a oportunidade de conviverem, de se conhecerem e concretizarem a intenção de integrarem a mesma família, é o período em que se estabelecerá uma base para a criação de vínculo afetivo entre as partes (NASCIMENTO, 2018, p. 18). Pois é no cotidiano, na rotina conjunta que surgirão as primeiras dificuldades.

O estágio de convivência é o período de avaliação da nova família, a ser acom-
panhado pela equipe técnica do juízo, com o intuito de verificar-se quanto à
adaptação recíproca entre adotando e adotante. Esta aferição se faz extrema-
mente necessária, pois não basta que o adotante se mostre uma pessoa equili-
brada e que nutre grande amor pelo próximo, uma vez que breve e superficial
contato nas dependências do juízo não garante aquilatarem-se as condições
necessárias de um bom pai ou boa mãe. Indispensável a realização de acompa-
nhamento do dia a dia da nova família, a fim de ser verificado o comportamento
de seus membros e como enfrentam os problemas diários surgidos pela convi-
vência. (BORDALLO, 2018, p. 406).

É durante esse período inicial de convívio diário, denominado de estágio de convivência, que podem surgir os primeiros conflitos inerentes à relação entre pais e filhos, questões que fazem com que os adotantes comecem a mudar o posicionamento sobre a adoção e, em muitas situações, acabar desistindo. Com relação às desistências nesse período, não há no ordenamento jurídico nenhuma norma que o proíba, inclusive, é prática comum e reiterada nos estágios de convivência que infelizmente acabam por gerar traumas a essas crianças e adolescentes. (PEDROZA, 2017, p. 20).

O prazo do estágio de convivência previsto pela lei 13.509/2017, no intuito de agilizar o procedimento, foi estabelecido em 90 dias, podendo esse prazo ser menor ou prorrogado por igual período, de acordo com o entendimento do magistrado. Quanto ao local, o estágio de convivência deverá ser cumprido em território nacional na comarca de residência da criança ou adolescente.

Concluído o estágio de convivência, é necessário iniciar a ação de adoção. E, durante a tramitação, o adotando ficará sob a guarda provisória dos adotantes. Transitada em julgada a ação de adoção, será expedido mandado de alteração do registro civil, sendo cancelado o registro anterior. Constituem-se, então, novas relações de parentesco, os adotantes constarão na certidão como pais e seus ascendentes como avós. Na nova certidão não poderá constar nenhuma referência quanto à condição de adotado ou origem biológica, como determina o $\S 4^{\circ}$ do art. 47 do ECA. (DIAS, 2017, p. 129-131).

Dimensão e os impactos da desistência da adoção

Para Gagliano e Barreto (2020, s.p.), a desistência pode ocorrer em três momentos: durante o estágio de convivência em sentido estrito; durante a guarda provisória para fins de adoção; ou após o trânsito em julgado da sentença de adoção. 
Iniciar o estágio de convivência, é a primeira etapa do convívio, significa já estar superado o momento em que os adotantes e o adotado ainda estão se conhecendo, então, começa a convivência rotineira, momento em que o adotado passará, mediante guarda, a viver com os adotantes, convivendo diariamente com a nova família que geralmente não se limita às figuras do pai e da mãe, mas inclui também a família extensa como avós, tios e primos e ampliam-se as expectativas do adotado com relação a essa nova realidade. Naturalmente, como acontece na constituição dos vínculos afetivos, com o passar do tempo, os vínculos e a afeição entre adotantes e adotado vão se estreitando.

\footnotetext{
Quanto mais tempo passa, mais se forma no adotando o sentimento de amor e carinho e a sensação de estar sendo aceito em um núcleo familiar, passando a sentir a segurança de ter uma família; a passagem do tempo forma, mais e mais, o senso de segurança e de estar sendo aceito no novo núcleo familiar (BORDALLO, 2018 p. 410).
}

Por óbvio, crianças institucionalizadas aguardam ansiosamente por uma nova família e criam expectativas sobre suas vidas futuras. Não é diferente com os adotantes, os quais geralmente buscam na adoção o ressarcimento de problemas de infertilidade, superação de perdas, entre outras respostas. A infertilidade é a principal delas. Os adotantes, momentaneamente tomados por tantas expectativas excessivas e desconhecendo os fatos acerca do abandono, idealizam características e comportamentos do filho adotado, algo que possivelmente será causa de desapontamentos em curto prazo. (NICOLAU, 2016, p. 28).

Quando a expectativa não corresponde à realidade esperada pelos pais adotivos, estes, após se depararem com as dificuldades de convivência e criação da criança adotada, despreparados, decidem "devolver" a criança à tutela do Estado (NASCIMENTO, 2018, p. 33). Destaca-se que antes da sentença, é possível a desistência do pedido de adoção. Isso pode ocorrer, p. ex., com o requerimento de adoção feito por "impulso" por candidatos à adoção despreparados emocionalmente que, depois, deparam-se com uma criança que não era propriamente aquilo que desejavam.

Nesses casos, difícil é negar a existência de danos das mais diversas ordens ao adotado. Acontece a frustração da expectativa de ter uma família culturalmente aceita, somada aos diversos rompimentos impostos pela situação da desistência. Aqueles que muitas vezes já vinham sendo chamados pelo adotado de "pai" e "mãe", pessoas pelas quais o adotado já nutria sentimentos de amor, respeito e que lhe davam a sensação de proteção, o abandonam.

\section{Fatores determinantes para a desistência da adoção}

Primeiramente, o termo desistência é mais adequado do que devolução, pois embora ele seja frequentemente usado, lembra muito mais bens materiais, objetos, coisas com defeito, portanto é inapropriado quando se refere a seres humanos que são dotados de dignidade (GAGLIANO; BARRETO, 2020, s.p.).

A adoção é, muitas vezes, erroneamente, observada de forma oposta à filiação biológica, como se o vínculo com o filho adotado pudesse ser extinto, pois ele é estabelecido juridicamente, enquanto o vínculo existente com o filho biológico, evidentemente, é impos- 
sível romper. Desse ponto de vista equivocado do instituto da adoção somado às questões árduas e desafios que necessariamente se apresentam nas relações familiares ao longo do tempo, nasce o desejo de desistir da adoção.

Cumpre observar que, em se tratando de adoção, por mais que seja uma escolha feita pelos pais por terem um filho, tal escolha não dá o direito a eles de desistir da filiação a qualquer tempo e por qualquer motivo. É preciso ter a ciência de que, assim como um filho biológico, um filho adotivo não pode ser tratado como uma experiência ou como uma filiação temporária. Ao decidir pela adoção e esta for efetivada, a relação de pai e filho é considerada como eterna, podendo jamais ser quebrada, exceto em casos extremos. (FALCÃO, 2017, p. 30).

Ao comentar a diferenciação cultural que se costuma fazer entre a filiação biológica e a filiação adotiva, Gagliano e Barreto (2020, s. p.) dizem que filhos biológicos podem apresentar os mesmíssimos problemas ou questões, sem que se cogite seu potencial de devolução e questiona: "E a quem se devolveria um filho biológico?" (GAGLIANO; BARRETO, 2020).

Ao conceituar adoção a partir do ordenamento jurídico brasileiro Diniz, explica que a posição de filho adotado será definitiva e irrevogável, para todos os efeitos legais, desligando o adotado de todo e qualquer vínculo de parentesco com os pais de sangue, salvo os impedimentos para o casamento, criando verdadeiros laços de parentesco entre o adotado e a família do adotante. Observa-se, portanto, que a legislação brasileira é precisa em determinar o caráter irrevogável da adoção, sendo a possibilidade de desistência da filiação apenas uma falsa ideia estabelecida culturalmente. (DINIZ, 2020, p. 597).

$\mathrm{Na}$ medida em que o comportamento do adotado começa a desafiar os pais, esse olhar errôneo do instituto da adoção começa a se acentuar pelas fantasias frustradas e até mesmo pelo olhar preconceituoso que se desenvolve ao longo do tempo a partir da cultura popular que insiste em se referir aos filhos adotivos como problemáticos, difíceis e condenados à repetição de condutas desajustadas de origem hereditária.

No imaginário social, prevalece a ideia de que os filhos adotivos são mais suscetíveis a conflitos afetivos e que a adoção, em si, constitui um campo propício a problemas. É comum nas produções científicas, tais como as publicações da mídia sobre adoção, haver a tendência a abordar as condutas, as vicissitudes e, principalmente, as dificuldades das crianças e adolescentes que vivem a condição de filhos adotivos. Até mesmo entre os profissionais (psicólogos, pediatras, fonoaudiólogos, professores, coordenadores de escolas etc), que lidam com crianças adotadas e que apresentam dificuldades, há a tendência de considerarem o fato de terem sido adotadas como o cerne de seus problemas ou sintomas. Não raras vezes, quando uma criança adotiva é encaminhada para psicodiagnóstico ou para psicoterapia, o fato de ter sido adotada torna-se o eixo do trabalho. A literatura também aponta uma tendência a considerar as famílias com casos de adoção mais vulneráveis a problemas relativos à educação dos filhos e a apresentar a adoção como fator de risco para alguns aspectos do desenvolvimento infantil. (SCHETTINI, 2007, p. 67).

É nesse momento, do aparecimento frequente de problemas comportamentais, de 
saúde ou de frustações, que os adotantes passam a cogitar a desistência da adoção, geralmente com argumentos pouco razoáveis e que, na verdade, são atravessamentos comuns na educação dos filhos, sejam eles biológicos ou adotivos como "menina que não gosta de ser contrariada", "sexualidade precoce" ou "menino hiperativo". O período da adolescência é considerado por alguns o mais conflituoso nas relações, pois é o período em que o adotado dará sinais de rebeldia e desobediência, comportamentos com os quais os pais, geralmente, possuem grande dificuldade. Mas, apesar do desassossego da adolescência, os conflitos geradores do desejo de desistir podem surgir em qualquer momento, por isso é tão importante o estágio de convivência, momento de análise da adaptação entre adotantes e adotado. Conflitos de convivência e problemas de comportamento são inerentes à relação entre pais e filhos, sejam eles biológicos ou adotados, a única diferença é a impossibilidade de "desistir" de um filho biológico. (NICOLAU, 2016, p. 27).

\subsection{Impacto psicológico e moral negativo da desistência para o adotado}

Se existe uma expectativa grande por parte dos adotantes, para o adotado não é diferente. Para as crianças e adolescentes institucionalizados os vínculos estreitos de afetividade comuns entre pais e filhos são desconhecidos ou, se conhecidos, remetem ao sofrimento intenso da rejeição e das lembranças do rompimento com a família biológica. Depois de todas as marcas deixadas por um processo de destituição, seguido de um período vivendo em instituições de acolhimento, é evidente e natural que os adotantes representem um alicerce emocional e despertem no adotado grandes expectativas de futuro, os quais passarão a visualizar nos novos pais apoio, segurança, estrutura, amor, enfim, todas as características que constituem uma infância digna.

Ainda que o estágio de convivência seja um período de adaptação, é provável que as crianças que vêm de um longo período em instituições de acolhimento não poupem expectativas com relação à concretização da adoção e do futuro ao lado da nova família, pois para elas é muito mais um momento burocrático do processo do que um momento de análise e experimentação e, "[...] ao contrário dos adultos, para uma criança não existe a compreensão de processo, documentos, sentença e estágio de convivência. Para ela, estar em um lar, convivendo com uma família, já significa ter sido adotada." (CARVALHO, 2017, p. 54).

Consequentemente, até mesmo durante o estágio de convivência, uma desistência será recebida com sofrimento e frustração pelos adotados, já que possuem uma visão consideravelmente diferente desse período, o que acaba gerando a repetição dos sentimentos de rejeição e abandono, em muitos casos, somado pela culpa, quando o adotado entende que não supriu as expectativas dos adotantes (FELIPE, 2016, p. 58).

A desistência de uma adoção, iniciado o estágio de convivência, é ato que indubitavelmente causa prejuízos nefastos ao adotando, que alimenta em si a esperança de que o ato será levado a cabo. A criança/adolescente, com a sua pureza, inocência e tranquilidade, não pode esperar algo diverso, sobretudo tendo um histórico de conflitos por conta de uma paternidade absolutamente irresponsável. Não seria capaz de exercer uma reserva mental acerca de seus sentimentos.

(REZENDE, 2014, p. 94). 
Outro fator, também prejudicial às adoções e à autoestima das crianças e dos adolescentes institucionalizados, é o estigma que elas sofrem, uma ideia sedimentada na sociedade de que essas crianças são mais suscetíveis a problemas de comportamento. É muito comum que os postulantes à adoção iniciem suas tentativas já com uma ideia pré-concebida de que necessariamente precisarão mais do que educar, mas dar suporte a uma saúde emocional violentada pela rejeição. Essa visão que os adotantes possuem de uma responsabilidade adicional na educação, é uma das ideias que faz com que ao encontrar as primeiras dificuldades, cresça o desejo da desistência que concretizada, estigmatiza os adotados por reiteradas tentativas frustradas de inserção familiar e causando-lhes prejuízo nas futuras relações afetivas.

[...] além do abalo e de todo o sofrimento psicológico sofrido pela criança ou pelo adolescente quando da sua devolução, além da dificuldade de serem posteriormente adotados, ainda há a probabilidade de que no futuro a vítima da devolução desenvolva condutas antissociais, uma vez que acaba absorvendo da experiência um entendimento de que as relações sociais não são dignas de confiança e que dificilmente encontrará alguém que satisfaça suas necessidades. (CARVALHO, 2017, p. 55).

A desistência, com o retorno das crianças ou dos adolescentes para o acolhimento institucional, violenta emocionalmente esses adotados, fazendo com que se sintam objetificados pelos adultos que, diferente deles, são donos de suas próprias decisões. Existe, para esses adotados, além da dor e da culpa de um segundo abandono, o constrangimento de retornar ao acolhimento institucional, o que os leva, muitas vezes a apresentarem o desejo de se isolar. Muitos manifestam a vontade de permanecer na instituição de acolhimento e de não serem adotados novamente, o que acaba sendo um mecanismo de defesa, colocar-se em uma posição de decisão para lidar com o sofrimento do momento e evitar o sofrimento do futuro. (CARVALHO, 2017, p. 54-55).

A responsabilidade civil no ordenamento jurídico brasileiro e a desistência de adoção

A responsabilidade civil é a aplicação de medidas que obriguem alguém a reparar dano moral ou patrimonial causado a terceiros em razão do ato do próprio imputado, da pessoa por quem ele responde, ou do fato da coisa ou animal sob sua guarda ou, ainda, da simples imposição legal. (DINIZ, 2020, p. 50).

Estatui o artigo 186 do Código Civil vigente: "Aquele que, por ação ou omissão voluntária, negligência ou imprudência, violar direito e causar dano a outrem, ainda que exclusivamente moral, comete ato ilícito" (BRASIL, 2002). Portanto, a responsabilidade civil se caracteriza por três elementos centrais: a conduta (ação do agente); o dano (doloso ou culposo); e o nexo de causalidade entre os dois primeiros. O primeiro elemento caracterizador da responsabilidade civil, a conduta humana, é o pressuposto indispensável para a configuração do dever de reparar. Essa conduta poderá ser positiva ou negativa, fazer e não fazer. O segundo elemento, a culpa, compreende o agir contrário ao ordenamento jurídico, 
voluntariedade na ação do agente, previsibilidade, sendo o dano causado previsível a partir da conduta, e a violação do dever de zelo. Posteriormente, observa-se o dano, o qual a essência da responsabilidade civil não existiria. $\mathrm{O}$ dano pode atingir o patrimônio ou causar prejuízos extrapatrimoniais, quando ofende a integridade física, psíquica ou moral. E, por fim, o nexo de causalidade, o qual significa a relação de causa e efeito existente entre o dano e a conduta do agente. (CARVALHO, 2017, p. 58).

A responsabilidade civil prevê duas espécies: contratual e extracontratual. Na temática da desistência da adoção, destaca-se a extracontratual, pois inexiste o ato negocial/ contratual entre pais e filhos. E, ainda, divide-se em objetiva e subjetiva, categorizações que se distinguem pela presença ou não do elemento culpa, gerador do dever de reparação. $\mathrm{Na}$ responsabilidade civil subjetiva, mesmo quando houver conduta, caso não caracterize culpa ou dolo, não há que se falar em responsabilidade. Já a responsabilidade civil objetiva caracteriza-se apenas pela existência de dano, conduta e nexo de causalidade. (CARVALHO, 2017, p. 59).

\footnotetext{
O Código Civil brasileiro, como se percebe na leitura do art. 186, filiou-se à teoria da responsabilidade civil subjetiva, que é utilizada como regra geral. Entretanto, em algumas situações verifica-se a adoção da teoria objetiva, como no art. 927 deste mesmo Código, que admite a responsabilidade independentemente de culpa quando causado um dano decorrente de exercício de alguma atividade que por sua própria natureza represente riscos. Ainda em outros casos verifica-se a adoção da teoria objetiva, como por exemplo, nos artigos 936, 937 e 938, que tratam, respectivamente, da responsabilidade do dono de animal, do dono do prédio em ruínas e do habitante de casa da qual caiam coisas, dentre outros artigos deste Código e também de outras leis esparsas. (CARVALHO, 2017, p. 59).
}

A aproximação entre o direito das famílias e a responsabilidade civil se estreitou nos últimos anos. Atualmente, a reparabilidade do dano moral, reconhecida como direito fundamental pela Constituição Federal de 1988, embora com muita resistência a sua aplicação no Direito de Família, passou a ser mais reconhecida nos danos decorrentes de relações familiares como, por exemplo, o fim de um casamento, o abandono afetivo e a alienação parental.

[...] a reparação civil está amparada pelo ordenamento jurídico como um todo, podendo obviamente ser inserida no âmbito familiar, tendo em vista a harmonização de todo o ordenamento jurídico, constituído de princípios, valores e normas de família muitas delas contidas na própria Magna Carta, regedora das demais leis, sendo, portanto, aplicável a todos os outros ramos do direito seja ele civil, familiar, sucessório ou obrigacional (SKAF, 2011, p. 11).

Para outros doutrinadores, o dever de indenizar não se sustentará a partir do ato ilícito previsto pelo artigo 186, mas pelo abuso de direito que está no artigo 187: "Também comete ato ilícito o titular de um direito que, ao exercê-lo, excede manifestamente os limites impostos pelo seu fim econômico ou social, pela boa-fé ou pelos bons costumes" (BRASIL, 2002). Caracteriza-se o abuso quando o exercício do direito for usado de forma desvirtuada, contrariando as finalidades preconizadas pela lei (NASCIMENTO, 2018, p. 31). 
3.1 Os instrumentos jurídicos para a reparação civil de crianças e de adolescentes vítimas de desistência de adoção e as limitações para a garantia da responsabilidade civil

Destacados alguns conceitos importantes da responsabilidade civil e seus reflexos no direito das famílias, deve-se observar inicialmente as hipóteses de desistência da adoção para que se possa pensar sobre a possibilidade de responsabilização civil em cada uma delas.

O primeiro momento em que cabe analisar a desistência de adoção é quando acontece durante o período do estágio de convivência, a qual conta com a hipótese de que não existe mecanismos legais de responsabilização civil, pois é o período de experimentação da convivência entre adotante a adotado. Formalmente, o estágio de convivência ainda é um momento de incerteza da adoção, portanto não poderia, nesse momento, falar-se em responsabilidade civil decorrente da desistência. A desistência durante esse período decorre do exercício regular de um direito. Mas existe, também, aqueles que não negam os danos decorrentes da desistência no estágio de convivência.

Em relação aos argumentos de que a devolução consiste em exercício regular de um direito e um dos fundamentos do estágio de convivência, estes não encontram guarida na melhor doutrina a respeito do estágio de convivência. [...] este existe com a finalidade de atender o melhor interesse da criança e do adolescente e o respeito a sua dignidade, verificando como o pai e a mãe solucionam os conflitos surgidos no cotidiano, se estão aptos a adotar a criança ou o adolescente em questão e ainda se esta adoção será a melhor solução para esta criança ou este adolescente. Sendo um direito instituído em favor da criança e do adolescente, não pode ser usado para mitigar seus direitos. Portanto, resta claro que o estágio de convivência não tem como objetivo servir de justificativa para que adotantes possam devolver uma criança ou adolescente que quiseram adotar e se isentem da responsabilidade. (CARVALHO, 2017, p. 63).

O estágio de convivência é, para uma criança ou um adolescente, mera formalidade. Apesar de ser uma verificação, deve ser considerado que o retorno ao acolhimento institucional nesse período poderá, também, causar sofrimentos intensos, pois é possível que o estágio ocorra por longo prazo e a afinidade entre os adotantes e o adotado se desenvolva com maior solidez. Portanto, desistir da adoção dentro do estágio de convivência não gera responsabilização civil dos desistentes, com exceção de situações excepcionais. Dessa forma, observados os casos concretos, algumas situações podem configurar a reparação civil. (GAGLIANO; BARRETO, 2020, s.p.).

Concluído com êxito o estágio de convivência, quando os adotantes manifestam o desejo de dar sequência no processo de adoção, é concedida a eles a guarda provisória para fins de adoção e nessa fase os adotantes já possuem alguns poderes parentais. A guarda provisória poderá ser concedida por tempo indeterminado, diferente do estágio de convivência que possui um tempo de duração limitado pela legislação de forma que a proximidade da 
convivência no período da guarda provisória é extremamente maior, sendo a desistência, nesse momento, mais dolorosa para o adotado. Diante do fato da guarda provisória, geralmente, se estender por um longo período de tempo, é comum que aumente a afeição do adotado com os adotantes e, com isso, maior será a frustração e os abalos decorrentes da desistência.

[...] depois de um estágio prolongado de guarda provisória - que, por vezes, dura anos e promove uma total inserção familiar do adotando no seio da família adotante - pode configurar abuso de direito, nos termos do art. $\underline{187}$ do $\underline{\text { Código }}$ Civil. E note-se que, nesse mencionado dispositivo (art. 187, CC), consagrou-se uma "ilicitude objetiva", vale dizer, que dispensa a demonstração do dolo ou da culpa para a sua configuração. (GAGLIANO; BARRETO, 2020, s.p.).

Diferentemente do estágio de convivência, será mais provável a responsabilização civil dos adotantes durante a guarda provisória, configurando, nesse momento, o abuso de direito, quando o vínculo familiar é constituído de forma forte suficiente para causar prejuízos à vítima. Na doutrina do abuso de direito é adotada a teoria objetiva da responsabilidade civil, quando não há necessidade de comprovação da culpa, sendo desconsiderada, também, a reprovação social da conduta. O artigo 187, pretende proteger a confiança recíproca existente na relação jurídica que há entre as partes. (PEDROZA, 2017, p. 24).

Mas o vínculo definitivo e irreversível da adoção se dará apenas com o trânsito em julgado da sentença, conforme o artigo $39, \S 1^{\circ}$ do Estatuto da Criança e do Adolescente. Assim, superados os períodos do estágio de convivência, da guarda provisória para fins de adoção e legalmente estabelecida a relação filiatória, ela será eterna. Não há no ordenamento jurídico nenhuma previsão legal de desistência. Os argumentos geralmente usados antes do trânsito em julgado para a "devolver" o adotado, nesse momento, já são muito carentes de convencimento, pois depois de um prolongado período de preparação imposto pelo trâmite do processo, seguido de razoável contato diário e intimidade proporcionados pelo estágio de convivência e pela guarda provisória, difícil se torna o entendimento de que as questões conflituosas não puderam ser observadas, mas sim de que se permitiram tais questões, renunciando o apoio da equipe técnica do judiciário.

Sendo irreversível a filiação constituída por adoção após o trânsito em julgado da sentença, a desistência deve gerar aos adotantes além do dever de indenizar, a exclusão de cadastro nacional de adoção com a impossibilidade de nova habilitação, obrigação alimentar, custeio de tratamentos psicológicos, entre outras necessidades que o adotado possa vir a apresentar, pois o poder familiar e as obrigações que dele derivam não podem ser renunciadas com tamanha facilidade. Também, é possível que o juízo não receba o pedido de desistência, considerando-o improcedente pela falta de previsão legal, o que poderá, além do dever de indenizar, gerar o ilícito penal de abandono de incapaz previsto no artigo 133 do Código Penal. (GAGLIANO; BARRETO, 2020, s.p.).

3.2 Limitações para a garantia de indenização ao adotado devolvido

Com relação ao estágio de convivência e a guarda provisória, ainda que tenha 
existido, entre ambos, longo período de convívio, não há na legislação vigente qualquer vedação à desistência antes do trânsito em julgado. Assim, o dever de indenizar será observado conforme a avaliação da equipe técnica acerca da saúde emocional do adotado devolvido, e não constatado real abalo psicológico a indenização poderá ser considerada desnecessária, conforme julgado do Tribunal de Justiça do Rio Grande do Sul:

APELAÇÃO CÍVEL. AÇÃO DECLARATÓRIA DE PATERNIDADE E MATERNIDADE SOCIOAFETIVA. ADOÇÃO. DESISTÊNCIA DO PEDIDO. ALIMENTOS. INDENIZAÇÃO POR DANO MORAL. I - O reconhecimento da paternidade socioafetiva requer apuração do vínculo de afetividade no âmbito social, além da posse de estado de filho. No entanto, demonstrada a renúncia expressa quanto ao desejo de serem os pais da criança, tendo os demandados desistido da adoção ainda quando tramitava o processo (fl. 110), aliada à ausência de vínculo afetivo entre eles, não há que se falar em reconhecimento da maternidade e paternidade socioafetiva. II - Igualmente, antes da sentença, não há lei que imponha obrigação alimentar aos demandados, que não concluíram o processo de adoção da criança. III - No caso, por mais triste e complexo que seja a situação, inexistindo efetivo prejuízo à integridade psicológica do indivíduo, que interfira intensamente no seu comportamento psicológico, causando aflição e desequilíbrio em seu bem estar, indefere-se o pedido de indenização por danos morais. RECURSO DO AUTOR DESPROVIDO, E PROVIDO O DOS DEMANDADOS. (TJRS. AC 0258681-13.2016.8.21.7000. Relatora: Liselena Schifino Robles Ribeiro. $7^{\text {a }}$ Câmara Civil. Julgado em: 31/08/2016. DJe 05/09/2016).

No recurso de apelação acima, os adotantes alegaram dificuldades com o comportamento do adotado, falta de entrosamento e forte vínculo com a família biológica, motivos pelo qual, segundo eles, a adoção não chegou a ser concretizada. A magistrada alegou inexistência de vedação legal a desistência de adoção. (NASCIMENTO, 2018, p. 42).

Verifica-se que a ausência de vedação legal à desistência da adoção, torna o dever de indenizar questionável, especialmente entre o estágio de convivência e a guarda provisória. Quando o fato não houver gerado a constatação de abalos morais e psicológicos, dificilmente será deferido o pedido de indenização, apesar de existir entendimentos de que a desistência dispensa a comprovação do abalo.

Muito comum é, também, o entendimento de que a prática de condenar os desistentes em indenização por danos morais, geraria um desestímulo aos futuros postulantes a adoção, posição que não merece prosperar, pois o referido desestímulo desencoraja somente os pretendentes à adoção irresponsável. Aqueles que de fato nutrem o desejo de constituir família, não estarão constrangidos frente a essa possibilidade. A indenização por danos morais suportados por crianças e adolescentes que retornam ao acolhimento institucional após uma adoção frustrada serve para consolidar o respeito à dignidade, à integridade moral e principalmente à condição peculiar de desenvolvimento. (REZENDE, 2014, s.p.).

\section{CONSIDERAÇOES FINAIS}

Com o advento da Constituição Federal de 1988, o Direito de Família e o Direito da Criança e do Adolescente ganharam novas interpretações, áreas que passaram a ser ob- 
servadas pelo ordenamento jurídico a partir do princípio da dignidade da pessoa humana, do reconhecimento da diversidade familiar, da prioridade absoluta e da afetividade. Logo, os institutos atinentes a essas áreas do direito passaram pelas mesmas alterações e com a adoção não foi diferente.

A adoção no Brasil, após a Constituição Federal de 1988, assume um novo papel, abandonando a pretensão única de garantir a descendência de uniões que por algum motivo não tiveram filhos biológicos e assumindo uma condição de promoção da dignidade de crianças e adolescentes privadas de suas famílias biológicas. Os lentos processos de adoção passam então a observar com primazia os interesses do adotado.

A morosidade do processo de adoção, constituída à longa espera em diversas etapas, não se mostrou suficiente para proporcionar aos adotantes uma ideia mais pragmática do ato de adotar e da construção dos vínculos após a adoção. Tornou-se comum, então, as tentativas de desistência da adoção em vários momentos, desde o estágio de convivência até depois do trânsito em julgado da sentença.

Impossível negar os expressivos prejuízos psíquicos e morais sofridos pelas crianças e pelos adolescentes devido às sucessivas rejeições, geralmente motivadas por questões pouco plausíveis que fazem surgir o questionamento se cabe a responsabilização civil por danos morais aos adotantes desistentes.

Constata-se que a indenização por danos morais a crianças e adolescentes vítimas de desistência de adoção é cabível em qualquer momento, inclusive nas desistências ocorridas durante o estágio de convivência, desde que comprovado que se constituiu vínculo de intensidade tão forte, capaz de desencadear prejuízos emocionais e morais ao adotado. Portanto, o não acompanhamento psicológico dos adotados devolvidos é um limitador para a garantia de indenização por danos morais, pois a percepção dos profissionais acerca da saúde emocional dessas crianças e adolescentes após a desistência determinará a possibilidade de indenização por danos morais.

\section{REFERÊNCIAS}

BRASIL. Lei $n^{\circ}$ 10.406, de 10 de janeiro de 2002. Institui o Código Civil. Diário Oficial [da] União, Brasília, DF, 10 jan. 2002. Disponível em: http://www.planalto.gov.br/ ccivil_03/leis/2002/L10406compilada.htm. Acesso em: 05 jul. 2021.

BRASIL. Lei n ${ }^{\circ}$ 8.069, de 13 de julho de 1990. Dispõe sobre o Estatuto da Criança e do Adolescente e dá outras providências. Diário Oficial [da] União, Brasília, DF, 13 jul. 1990. Disponível em: http://www.planalto.gov.br/ccivil_03/leis/18069.htm. Acesso em: 05 jul. 2021.

BRASIL. Constituição (1988). Constituição da República Federativa do Brasil. Diário Oficial [da] República Federativa do Brasil, Brasília, DF, 5 out. 1988. Disponível em: . Acesso em: 02 jul. 2021. 
BORDALLO, Galdino Augusto Coelho. Adoção. In: MACIEL, Kátia Regina Ferreira Lobo Andrade (Coord.). Curso de Direito da Criança e do Adolescente: Aspectos teóricos e práticos. $11^{\mathrm{a}}$.ed. São Paulo: Saraiva Educação, 2018.

CARVALHO, Larissa Grouiou de. Responsabilidade civil dos adotantes pela devolução da criança e do adolescente adotado. 2017. 92f. Monografia - Universidade Federal de Alagoas, Maceió, 2017.

DIAS, Maria Berenice. Filhos do Afeto. 2. ed. São Paulo: Ed. RT, 2017.

DINIZ, Maria Helena. Curso de Direito Civil Brasileiro. Volume 5: direito de família. 34. ed. São Paulo: Saraiva, 2020.

FALCÃO, Débora Lima Marinho. Devolução de crianças adotadas: A reedição do abandono e o sistema legal de proteção da criança, em caso de devolução. 53f. Monografia Universidade Federal de Pernambuco, Recife, 2017.

FARIAS, Cristiano Chaves de; ROSENVALD, Nelson. Curso de Direito Civil. Volume 6: famílias. 9.ed. Salvador: Juspodivm, 2017.

FELIPE, Luiza. A responsabilidade civil dos pretendentes à adoção nos casos de desistência da medida durante o estágio de convivência. 2016. 83f. Monografia - Universidade Federal de Santa Catarina, Florianópolis, 2016.

GAGLIANO, P. S.; BARRETTO, F. C. L. Responsabilidade civil pela desistência da adoção. IBDFAM, Belo Horizonte, v. 1, n. 1, jul. 2020. Disponível em: https://ibdfam.org. br/artigos/1513/Responsabilidade + civil + pela + desist $\% C 3 \% A A n c i a+$ na + ado $\% C 3 \% \mathrm{~A} 7 \%$ C3\%A3o. Acesso em: 04 abr. 2021.

LÔBO, Paulo. Direito Civil. Volume 5: famílias. 8.ed. São Paulo: Saraiva, 2018.

MADALENO, Rolf. Manual de Direito de Família. 2.ed. Rio de Janeiro: Forense, 2019.

MOREIRA, Rafael Bueno da Rosa; MARINHO, Fernanda Vargas. A responsabilidade civil pelos danos inerentes a desistência da adoção de crianças e adolescentes, Revista Jurídica em Pauta, Bagé, Ano 1- nº 2, p. 91-110, 2019.

NASCIMENTO, Rayane Lima. Responsabilidade Civil por Desistência da Adoção. $51 \mathrm{f}$. Monografia - Centro Universitário Toledo, Araçatuba, 2018.

NICOLAU, Flávia de Almeida. Da (im)possibilidade da responsabilidade civil decorrente da devolução da criança ou adolescente adotado. 2016. 58f. Trabalho de conclusão de curso - Fundação Universidade Federal de Rondônia - UNIR, Cacoal, 2016. 
PEDROZA, Munnik Tayla Ribeiro. Responsabilidade civil em casos de desistência de adoção. 2017. 58f. Monografia - Universidade de Brasília, Brasília, 2017.

REZENDE, Guilherme Carneiro de. A responsabilidade civil em caso de desistência da adoção, Revista Jurídica do Ministério Público do Estado do Paraná, Curitiba, Ano 1 n. ${ }^{\circ} 1$, p. 81-103, dez. 2014. Disponível em: <http://www.crianca.mppr.mp.br/arquivos/File/ publi/mppr/revista_juridica_mppr_n01_2014.pdf $>$ Acesso em: 02 jul. 2021.

RIEDE, Jane Elisabete; SARTORI, Giana Lisa Zanardo. Adoção e os Fatores de Risco: Do Afeto à Devolução das Crianças e Adolescentes. 2013, Perspectiva, v. 37, n. 138, p. 143 154, Erechim, jun. 2013. Disponível em:

http://www.uricer.edu.br/site/pdfs/perspectiva/138 354.pdf. Acesso em: 02 jul. 2021.

ROSSATO, Luciano Alves; LÉPORE, Paulo Eduardo. Comentários à Lei Nacional da Adoção - Lei 12.010, de agosto de 2009. São Paulo: Revista dos Tribunais, 2009.

SKAF, Samira. Responsabilidade civil decorrente do abandono afetivo paterno - filial. 2011, IBDFAM. Disponível em:

http://www.ibdfam.org.br/artigos/766/Responsabilidade+civil+decorrente+de+abandono+afetivo+paterno-filial. Acesso em: 02 jul. 2021.

SCHETTINI, Suzana Sofia Moeller. Filhos por adoção: um estudo sobre o seu processo educativo em famílias com e sem filhos biológicos. 2007. 213f. Dissertação - Universidade Católica de Pernambuco - Pernambuco, 2007.

ZAPATER, Maíra. Direito da Criança e do Adolescente. São Paulo: Saraiva, 2019.

\section{DADOS DOS AUTORES}

\section{André Viana Custódio}

Doutor em Direito pela Universidade Federal de Santa Catarina (UFSC) - SC. Pós-doutor em Direito pela Universidade de Sevilha - Espanha. E-mail: andreviana.sc@gmail.com

\section{Maurício Nader Griguc}

Bacharel em Direito na Universidade de Santa Cruz do Sul. E-mail: mgriguc@hotmail.com

Submetido em: 2-7-2021

Aceito em: 27-9-2021 